\title{
RESISTÊNCIA MECÂNICA A FRIO E A QUENTE DE PELOTAS AUTORREDUTORAS DE MINÉRIO DE FERRO*
}

\author{
Carolina Person Maschio ${ }^{1}$ \\ Cyro Takano ${ }^{2}$ \\ Marcelo Breda Mourão ${ }^{3}$ \\ Tiago Ramos Ribeiro ${ }^{4}$ \\ Sandra Lucia de Moraes ${ }^{5}$
}

\section{Resumo}

Pelotas compostas de minério de ferro, aglomerante e coque foram analisadas quanto à resistência à compressão (a frio e após aqueciemento) e porosidade. Para isso, três lotes de pelotas foram confeccionados, com diferentes teores de redutor, até a quantidade necessária para reação completa com os óxidos de ferro. Após seu preparo, as pelotas passaram por diferentes tempos de cura ao ar. Ensaios de resistência à compressão à frio e porosidade foram realizados em pelotas verdes e com 3, 7, 14, 21 e 28 dias de cura. Após 28 dias, uma série de pelotas foram secas e submetidas a testes de resistência à compressão após serem aquecidas a temperaturas entre $200^{\circ} \mathrm{C}$ a $900^{\circ}$. Analisou-se, também, a perda de massa em cada patamar de temperatura. Entre os principais resultados, verificou-se que 0 comportamento mecânico de pelotas autorredutoras é melhorado com o aumento do tempo de cura e prejudicado pelo aumento do teor de coque e aumento da temperatura. Após $600^{\circ} \mathrm{C}$, a resistência das pelotas cai potencialmente. Além disso, lotes com maiores teores de coque apresentaram maiores valores de porosidade, sendo que este aumento foi mais significativo nos primeiros dias de cura.

Palavras-chave: Minério de ferro; Autorredutoras; Resistência à compressão; Tempo de cura.

\section{MECHANICAL BEHAVIOR OF SELF-REDUCING PELLETS FROM IRON ORE}

\begin{abstract}
Composite pellets of Iron ore with binder and coke were analyzed for their cold and hot behaviors, such as compressive strength and porosity. For this, three batches of pellets were prepared, with different reducer contents, until the amount needed for complete reaction with the iron oxides. The amount of binder was set at $8 \%$. After preparation, the pellets were separated into samples that would undergo different curing times in the air. Tests of cold compressive strength and porosity were performed for green pellets and with $3,7,14,21$ and 28 of curing days. After 28 days, batches of pellets were dried and subjected to tests of hot compressive strength, varying temperatures from $200^{\circ} \mathrm{C}$ to $900^{\circ}$. The mass loss at each temperature plateau was also analyzed. From results, it was verified that the mechanical behavior of self-reducing pellets is improved with the increase of curing time and impaired by the increase of the coke content and increase in temperature. After $600^{\circ} \mathrm{C}$, the resistance of the pellets falls potentially. In addition, batches with higher coke content had higher values of porosity, and this increase was more significant in the first days of cure.
\end{abstract}

Keywords: Self-reducing; Iron ore; Binder; Hot and cold behaviors, compressive strength, cure.

Graduanda em Engenharia de Materiais. Departamento de Engenharia Metalúrgica e de Materiais, Escola Politécnica da Universidade de São Paulo, São Paulo, SP, Brasil. 
2 Associado da ABM. Eng. Metalurgista, Doutor e Livre Docente, Prof. Sênior, Departamento de Engenharia Metalúrgica e de Materiais, Escola Politécnica da Universidade de São Paulo, São 3.

3 Associado da ABM. Eng. Metalurgista, Doutor e Livre Docente, Prof. Associado, Departamento de Engenharia Metalúrgica e de Materiais, Escola Politécnica da Universidade de São Paulo, São Paulo, SP, Brasil.

4 Associada da ABM. Eng. Química, Doutora, responsável pelo Laboratório de Processos Metalúrgicos/CTMM. Instituto de Pesquisas Tecnológicas do Estado de São Paulo, São Paulo, $S P$, Brasil.

1 Engenheiro Metalurgista, Mestre, Pesquisador, CTMM/LPM, Instituto de Pesquisas Tecnológicas do Estado de São Paulo, São Paulo, SP, Brasil. 


\section{INTRODUÇÃO}

O Brasil é um fornecedor mundial de minério de ferro. Entre os consumidores de minério estão os produtores de ferro-esponja que se utilizam dos chamados processos de redução direta. Estes processos realizam a redução dos óxidos de ferro por reação com gases redutores $\left(\mathrm{CO}\right.$ e $\left.\mathrm{H}_{2}\right)$ aquecidos que fluem em contracorrente a um leito descendente de pelotas de minério de ferro [1].

O setor Siderúrgico vem sendo reestruturado nos últimos anos, buscando processos mais eficientes e que agridam menos o meio ambiente. Assim, os processos de redução direta, que utilizam gás natural como redutor, têm surgido como uma alternativa aos processos mais comuns vigentes até então, onde se utilizava fontes fósseis de carbono gerando mais $\mathrm{CO}_{2}$.

Uma das limitações para aumento da eficiência dos processos de redução é a velocidade da reação entre o minério e os redutores sejam estes sólidos ou gasosos. Uma das ideias apresentadas na literatura [2-4] para melhorar esta velocidade é o uso de pelotas autorredutoras. Na autorredução o redutor é adicionado no aglomerado, o que permite o aproveitamento de minério de ferro de granulometria muito fina e fonte de carbono diversificada, seja carvão, coque ou carvão vegetal [5]. Desta forma, as partículas do minério e do redutor estarão em contato próximo e os gases do processo de redução são gerados no interior da própria pelota. Isto reduz o tempo de redução de horas como no alto forno ou nos processos de autorredução para tempos menores que 10 minutos [3].

O comportamento mecânico destas pelotas é um fator crítico para o uso industrial. Propriedades mecânicas devem ser atingidas para que não haja degradação excessiva durante o transporte, manuseio e na sua utilização propriamente dita [5]. A geração excessiva de finos afeta a permeabilidade da carga e compromete a operação estável do equipamento.

Muitos dos estudos realizados sobre o uso de pelotas autorredutoras foca no altoforno [6] ou em processos desenvolvidos especificamente para o uso deste material [7]. Nestes casos, utiliza-se a quantidade exata ou um pouco de excesso para redução completa dos óxidos de ferro. Isto traz uma complexidade na formação da pelota, pois os materiais carbonáceos possuem baixa densidade e passam a corresponder por um volume de aproximadamente $40 \%$ da pelota. Como consequência, é necessário um uso maior de aglomerante a fim de garantir a estabilidade estrutural da pelota.

Nestes processos é possível pensar numa redução combinada, sendo parte realizada por reação com o gás redutor e parte pelo carbono da pelota. Isto permite a utilização de menores teores de redutor sólido na composição da pelota. Este será o foco do presente trabalho. Assim, será estudado o comportamento mecânico a frio e a quente de pelotas autorredutoras de minério de ferro contendo quantidade de redutor inferior à necessária para reação completa com os óxidos de ferro. Além disso, este projeto visa analisar a influência do tempo de cura na porosidade de pelotas com diferentes proporções minério-redutor.

\subsection{Revisão Bibliográfica}

O processo de redução dos óxidos de ferro pelo carbono acontece em sua quase totalidade por reações do tipo sólido-gás (Equações 2 a 5), sendo o óxido reduzido principalmente pelo gás $\mathrm{CO}$. Apenas uma pequena fração da reação acontece segundo uma reação sólido-sólido (Equação 1) e, por este motivo, costuma-se desprezar sua contribuição [8]. 
Reação sólido-sólido:

$\mathrm{Fe}_{2} \mathrm{O}_{3(\mathrm{~s})}+3 \mathrm{C}_{(\mathrm{s})} \rightarrow 2 \mathrm{Fe}_{(\mathrm{s})}+3 \mathrm{CO}_{(\mathrm{g})}$

Reação sólido-gás:

$$
\begin{array}{r}
3 \mathrm{Fe}_{2} \mathrm{O}_{3(\mathrm{~s})}+\mathrm{CO}_{(\mathrm{g})} \rightarrow 2 \mathrm{Fe}_{3} \mathrm{O}_{4(\mathrm{~s})}+\mathrm{CO}_{2(\mathrm{~g})} \\
\mathrm{Fe}_{3} \mathrm{O}_{4(\mathrm{~s})}+\mathrm{CO}_{(\mathrm{g})} \rightarrow 3 \mathrm{FeO}_{(\mathrm{s})}+\mathrm{CO}_{2(\mathrm{~g})} \\
\mathrm{FeO}_{(\mathrm{s})}+\mathrm{CO}_{(\mathrm{g})} \rightarrow \mathrm{Fe}_{(\mathrm{s})}+\mathrm{CO}_{2(\mathrm{~g})} \\
\mathrm{C}_{(\mathrm{s})}+\mathrm{CO}_{2(\mathrm{~g})} \rightarrow 2 \mathrm{CO}_{(\mathrm{g})}
\end{array}
$$

É sabido que o processo de redução do óxido de ferro não possui estequiometria definida, os valores dos coeficientes dependem das velocidades das reações parciais. A reação global pode ser representada pela Equação 6, onde os valores dos coeficientes $p$, $u$ e $v$ dependem das constantes de equilíbrio e das velocidades das reações parciais [2]:

$$
\mathrm{Fe}_{2} \mathrm{O}_{3(\mathrm{~s})}+\mathrm{pC}(\mathrm{s}) \rightarrow 2 \mathrm{Fe}_{(\mathrm{s})}+\mathrm{uCO}_{(\mathrm{g})}+\mathrm{vCO}_{2(\mathrm{~g})}
$$

Em geral, na medida em que a temperatura sobe, fica garantida a predominância volumétrica do $\mathrm{CO}$ sobre o $\mathrm{CO}_{2}$, obtendo-se um caso particular da equação 6 :

$$
\mathrm{Fe}_{2} \mathrm{O}_{3(\mathrm{~s})}+3 \mathrm{C}_{(\mathrm{s})} \rightarrow 2 \mathrm{Fe}_{(\mathrm{s})}+3 \mathrm{CO}_{(\mathrm{g})}
$$

Com essa última equação, pode-se determinar as quantidades em massa de cada componente da pelota para uma condição 100\% estequiométrica, por meio da composição destes.

A pelotização de finos é um processo baseado no molhamento, rotação e aglomeração dos mesmos [9]. Entre os fatores que permitem a aglomeração de partículas estão o fenômeno da capilaridade e a compactação sofrida pelo material durante sua rotação.

A formação das pelotas ocorre em duas fases: formação de núcleos e o crescimento destes. Os núcleos começam a ser formados pela da adição de água à mistura, em quantidade específica calculada para cada tamanho de lote. A adição demasiada de água faz com que os aglomerantes percam efetividade durante o processo de pelotização devido à capilaridade. Existe um ponto ótimo para a adição do líquido, onde o efeito das pontes líquidas mais o efeito da capilaridade são máximos [10]. 0 crescimento dos núcleos se dá pelo contínuo acréscimo da mistura e água, até atingir o tamanho desejado.

A quantidade de cimento utilizado é um fator decisivo para obtenção da melhor propriedade mecânica possível, e está relacionada à formação de uma camada sobre a superfície entre as partículas. Medidas acima de $8 \%$ de aglomerante, ou seja, que formam mais de uma camada sob as partículas prejudicam a resistência final do aglomerado [2]. A faixa entre 6 e $8 \%$ de aglomerante tem taxas de aumento de resistência mecânica mais significativas [11].

A cura de pelotas autorredutoras usando cimento em sua composição envolve mudanças físico-químicas nos constituintes do aglomerante, que ocorrem em baixas temperaturas e na presença de umidade suficiente para o desenvolvimento das reações de hidratação [12]. Essas reações ocorrem com a formação de um complexo de cálcio e silício hidratado tipo gel, assim como ocorre no concreto. Existe também a reação de carbonatação, mas a mesma pode ser desprezada quando as pelotas passam por pequenos tempos de cura e dado ao fato das pelotas serem feitas numa atmosfera normal, que representa baixa pressão parcial de $\mathrm{CO}_{2}[2]$. 


\section{MATERIAIS E MÉTODOS}

\subsection{Materiais}

As pelotas foram confeccionadas a partir de minério de ferro (pellet feed), aglomerante e redutor, as respectivas análises químicas e granulométricas estão nas Tabelas 1 e 2. O minério de ferro foi fornecido pela Vale. O aglomerante utilizado foi o cimento CPV-ARI, de alta resistência inicial, a fim de conferir resistência mecânica às pelotas durante o processo de cura. $O$ redutor foi o coque de petróleo (UNICARBO 10) da Unimetal, com a função de reduzir o óxido de ferro tanto por reações sólido-sólido como por reações sólido-gás [10].

Tabela 1. Análise Química (base seca) dos constituintes das pelotas autorredutoras.

\begin{tabular}{|c|c|c|c|}
\hline Componentes & $\begin{array}{l}\text { Pellet } \\
\text { feed }\end{array}$ & Aglomerante & Coque \\
\hline $\mathbf{F e}$ & 65,9 & $2,6(\mathrm{Fe} 2 \mathrm{O} 3)$ & - \\
\hline $\mathrm{SiO}_{2}$ & 2,3 & 21,4 & - \\
\hline $\mathrm{Al}_{\mathbf{2}} \mathbf{O}_{3}$ & 0,3 & 4,8 & - \\
\hline $\mathbf{S}$ & - & - & 0,7 \\
\hline $\mathbf{P}$ & 0,02 & - & - \\
\hline $\mathbf{M n}$ & 0,05 & - & - \\
\hline $\mathbf{C a O}$ & 0,6 & 59,7 & - \\
\hline $\mathbf{M g O}$ & 0,03 & 2,7 & - \\
\hline $\mathbf{T i O} \mathbf{O}_{2}$ & 0,05 & - & - \\
\hline $\mathbf{C}$ & 1,1 & - & 99,5 \\
\hline $\mathbf{P P C}$ & 2,2 & 3,4 & - \\
\hline SO3 & 3,1 & - & - \\
\hline Na2O & 0,2 & - & - \\
\hline K2O & 0,8 & - & - \\
\hline S2- & 0,05 & - & - \\
\hline voláteis & - & - & 0,4 \\
\hline cinzas & - & - & 0,1 \\
\hline umidade & 4,0 & 1,6 & 0,3 \\
\hline
\end{tabular}

Tabela 2. Análise Granulométrica dos componentes das pelotas autorredutoras.

\begin{tabular}{|c|c|c|c|}
\hline Mesh & Pellet Feed & Aglomerante & Coque \\
\hline+ 100\# & $0,7 \%$ & $7,4 \%$ & $0 \%$ \\
\hline - 100\#+ 150\# & $0,6 \%$ & $1,1 \%$ & $0 \%$ \\
\hline - 150\#+ 200\# & $2,9 \%$ & $2,8 \%$ & $0,8 \%$ \\
\hline - 200\#+ 270\# & $6,9 \%$ & $7,8 \%$ & $12,9 \%$ \\
\hline - 270\# + 325\# & $12,5 \%$ & $13,0 \%$ & $14,2 \%$ \\
\hline - 325\#+4 400\# & $14,8 \%$ & $11,7 \%$ & $14,5 \%$ \\
\hline -400\# & $61,7 \%$ & $56,2 \%$ & $57,6 \%$ \\
\hline
\end{tabular}

\subsubsection{Pelotização}

As pelotas confeccionadas foram subdivididas em três lotes: $25 \%\left(P \_25\right), 50 \%$ (P_50) e 100\% (P_100), onde os teores de carbono são $25 \%, 50 \%$ e $100 \%$ do teor carbono estequiométrico, respectivamente. A composição de cada lote está descrita na Tabela 3. O cálculo da quantidade de minério e coque foi realizado por meio de 
balanço de massa, com os fundamentos apresentados na revisão bibliográfica utilizando-se a equação 7 .

Tabela 3. Porcentagem em massa de cada lote de pelota a ser confeccionado.

\begin{tabular}{|c|c|c|c|}
\hline Lote & Minério de Ferro & Cimento & Coque \\
\hline P_25 & $88,4 \%$ & $8 \%$ & $3,6 \%$ \\
\hline P_50 & $84,1 \%$ & $8 \%$ & $7,9 \%$ \\
\hline P_100 & $76,7 \%$ & $8 \%$ & $15,3 \%$ \\
\hline
\end{tabular}

Para o preparo de cada lote, o coque, o minério de ferro e o cimento foram misturados em misturador intensivo EIRICH por cerca de cinco minutos, nas quantidades indicadas pela Tabela 4. A mistura foi então levada a um disco de pelotização de 1,2 metros de diâmetro, com rotação de 25 rpm e inclinação de 45으, simulando o processo industrial de pelotização. Através da contínua adição de mistura e água, os núcleos se formaram e cresceram, até atingir valores necessários para o projeto, entre $9 \mathrm{~mm}$ e $16 \mathrm{~mm}$.

Tabela 4. Quantidades em massa (gramas) de cada material adicionado aos lotes P_25, P_50 e P_100.

\begin{tabular}{|l|l|l|l|}
\hline Material & P_25 & P_50 & P_100 \\
\hline minério & 5792,3 & 5388,1 & 5801,2 \\
\hline coque & 203,0 & 490,3 & 1116,6 \\
\hline cimento & 453,8 & 458,2 & 590,3 \\
\hline água & 322,7 & 287,2 & 385,7 \\
\hline \% água & $4,8 \%$ & $4,3 \%$ & $4,9 \%$ \\
\hline
\end{tabular}

\subsection{Métodos}

Após a pelotização, as pelotas foram separadas em diferentes amostras, de acordo com o tempo de cura ao ar que cada uma seria submetida, para serem realizados ensaios de compressão e porosidade - a fim de verificar o comportamento mecânico das pelotas autorredutoras. Foram realizados testes com pelotas sem passar por processo de cura também, denominadas verde. Para os ensaios de resistência à compressão cada amostra era composta de 10 pelotas. Já amostras que passariam por testes de porosidade possuíam 5 pelotas.

Para cada lote de pelotas confeccionado, amostras foram submetidas a tempos de cura de 3, 7, 14, 21 e 28 dias. Os ensaios mencionados foram realizados também com amostras verde, verde seca - que passaram pelo processo de secagem em estuda a 105ㄷ logo após sua formação - e secas após 28 dias.

Ensaios de resistência à compressão foram realizados também com pelotas secas e curadas submetidas a diferentes patamares de temperatura: $200^{\circ}, 300^{\circ}, 500^{\circ}, 700^{\circ} \mathrm{e}$ $900^{\circ} \mathrm{C}$. Cada amostra submetida aos respectivos ensaios possuíam 3 pelotas, que foram aquecidas a uma taxa de 10\%/min, em atmosfera inerte com vazão de nitrogênio de $0,06 \mathrm{~m}^{3} / \mathrm{h}$. Após certo tempo no patamar, a amostra foi resfriada a temperatura ambiente. Foram realizados ensaios em que a amostra permaneceu 30 minutos nos patamares citados. Além disso, para as temperaturas de $700^{\circ}$ e $900^{\circ} \mathrm{C}$ realizaram-se também testes para amostras permanecendo 10 e 50 minutos em cada patamar. 
O ensaio de resistência à compressão foi realizado em prensa mecânica EMIC, medindo-se a carga máxima suportada por cada corpo de prova até sua ruptura. O diâmetro de cada pelota foi medido com auxílio de um paquímetro e normalizado para um diâmetro padrão de 12,5 milímetros, considerando-se que a resistência à compressão de uma esfera é proporcional ao quadrado do seu diâmetro.

A medição da porosidade das pelotas foi feita por meio de um Porosímetro Automático. O sistema é composto por um computador padrão IBM-PC, uma balança de precisão OHAUS Adventurer, uma câmera de vídeo CCD Hitachi e uma mesa de luz giratória para suporte da pelota ensaiada.

\section{RESULTADOS E DISCUSSÃO}

\subsection{Ensaio de Resistência à Compressão a Frio}

As médias dos valores de carga máxima suportada por cada corpo de prova, até ocorrer ruptura do mesmo, com os diferentes tempos de cura ao ar estão representadas na Tabela 5. A evolução da resistência mecânica a frio desses lotes de acordo com o tempo de cura encontra-se na Figura 1.

Tabela 5. Carga máxima suportada e número de quedas de cada lote de pelotas em diferentes tempos de cura. Valores normalizados para o diâmetro de $12,5 \mathrm{~mm}$.

\begin{tabular}{|c|c|c|c|c|c|c|c|c|}
\hline \multirow{2}{*}{ Lote } & \multicolumn{7}{|c|}{ Resistência à compressão (kgf) } \\
\cline { 2 - 9 } & Verde & $\begin{array}{c}\text { Verde } \\
\text { (seca) }\end{array}$ & $\mathbf{3}$ dias & $\mathbf{7}$ dias & $\mathbf{1 4}$ dias & $\mathbf{2 1}$ dias & $\mathbf{2 8}$ dias & $\begin{array}{c}\mathbf{2 8} \\
\text { dias(seca) }\end{array}$ \\
\hline P_25 & $0,83 \pm 0,09$ & $1,34 \pm 0,1$ & $6,83 \pm 0,87$ & $6,87 \pm 0,84$ & $7,69 \pm 1,04$ & $10,52 \pm 0,88$ & $8,6 \pm 0,94$ & $9,3 \pm 0,9$ \\
\hline P_50 & $0,8 \pm 0,06$ & $1,11 \pm 0,05$ & $9,12 \pm 0,84$ & $10,05 \pm 0,88$ & $11,22 \pm 0,64$ & $10,18 \pm 0,69$ & $11,09 \pm 1,34$ & $11,73 \pm 0,99$ \\
\hline P_100 & & $0,88 \pm 0,08$ & & $6,77 \pm 0,99$ & $6,87 \pm 0,81$ & $7,8 \pm 1,21$ & $7,87 \pm 0,93$ & $6,48 \pm 0,69$ \\
\hline
\end{tabular}

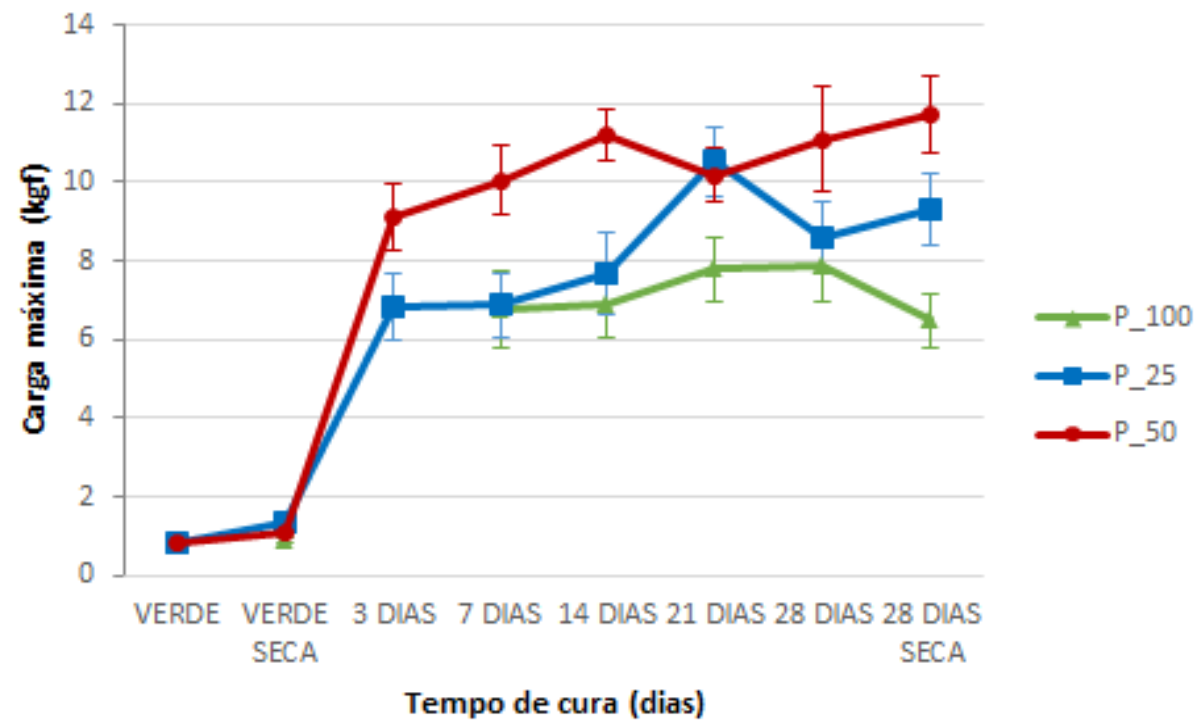

Figura 1. Carga máxima suportada por cada lote em diferentes tempos de cura, com intervalo de confiança de $95 \%$.

As propriedades mecânicas são altamente elevadas durante os primeiros dias de cura, devido a fácil hidratação inicial dos componentes do cimento. Este estágio foi 
observado experimentalmente até o terceiro dia de cura. A reação de hidratação pode formar produtos mais complexos, mas baseado na teoria coloidal, é razoável admitir que a coesão entre as partículas é dada pela precipitação de um tipo de gel coloidal que endurece devido à reação com água [13]. Esse gel possui uma estrutura porosa e tende a alcançar uma fase termodinamicamente mais estável. Conforme os novos cristais de silicatos hidratados são formados, primeiramente tricálcio silicato $\left(\mathrm{C}_{3} \mathrm{~S}\right)$, as propriedades mecânicas dos aglomerados são melhoradas.

O segundo estágio do aumento da resistência à compressão pode ser atribuído a maior hidratação do di-cálcio silicato $\left(\mathrm{C}_{2} \mathrm{~S}\right)$. A melhor resistência é alcançada normalmente dentro de 3 ou 4 semanas, como ocorre normalmente com o cimento comum [2]. Em cimentos de pega rápida, por conter maior quantidade de $\mathrm{C}_{3} \mathrm{~S}$, a cura ocorre até em menos de uma semana.

Nota-se que a resistência mecânica das pelotas melhorou com maior intensidade nos primeiros 3 dias de cura, como era esperada devido à utilização de cimento de alta resistência inicial. Após este período não houve muita variação.

A taxa da reação de hidratação é favorecida com o aumento da temperatura até certo valor [14]. Para a temperatura experimental de secagem, de $105^{\circ} \mathrm{C}$, nota-se que as pelotas verdes secas, praticamente não melhoraram, em termos de resistência mecânica, indicando que a velocidade de vaporização é mais intensa que de reação de hidratação.

A quantidade de coque na pelota é um fator bastante relevante para seu comportamento mecânico. Maiores quantidades de coque acabam prejudicando a resistência à compressão das pelotas. Por ser hidrofóbico, o coque dificulta a coesão entre partículas durante a pelotização e compromete a reação do cimento com a água, que originaria o gel coloidal endurecedor da pelota. Quanto maior a quantidade de coque na pelota, menor é a ligação entre as partículas e menor o envolvimento dessas partículas com o cimento. Consequentemente, menor a resistência mecânica da pelota.

No entanto, o lote P_25, que deveria ter os maiores valores de carga máxima suportada, se mostrou menos resistente à compressão que o lote P_50. As pelotas P_25 e P_50 foram analisadas e verificadas que os teores de carbono estavam corretos. Esses resultados não condizentes com o esperado é ainda uma questão aberta. Eles podem ser decorrentes de algum fenômeno que necessita de maior compreensão.

\subsection{Ensaio de Porosidade}

Os resultados de porosidade obtidos para cada lote, nos diferentes tempos de cura, estão representados pela Figura 2. Esses valores são a média dos valores verificados em cada pelota da amostra.

Pode-se observar que a porosidade da pelota está diretamente relacionada ao teor de coque presente nela, devido ao aumento do teor de carbono. Nota-se também que a porosidade das pelotas aumentou significantemente nos primeiros dias de cura, condizentes com os resultados da resistência à compressão. Como mencionado anteriormente, nos primeiros dias de cura ocorrem reações de hidratação e formação de gel coloidal de estrutura porosa. 


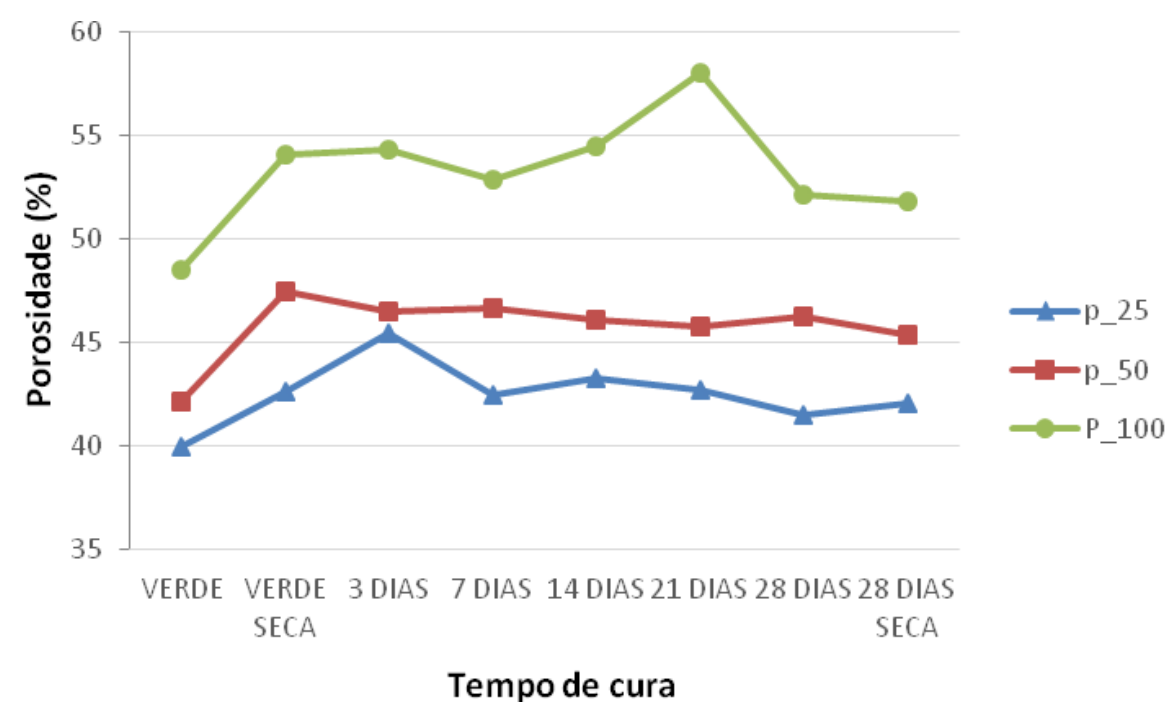

Figura 2. Porosidade média de cada lote em diferentes tempos de cura.

Pelotas convencionais costumam ter entre 20 e $30 \%$ de porosidade. 0 disco de pelotização na indústria chega a medir até 10 metros, garantindo uma compactação muito alta devido ao impacto gerado pelas paredes do disco. Já as pelotas utilizadas nesse projeto foram pelotizadas em um disco de 1,2 metros, tendo um impacto bem menor e, portanto, menor compactação, o que explica os valores mais altos de porosidade, além do efeito do teor de carbono.

\subsection{Ensaio de Resistência à Compressão Após Aquecimento}

As médias dos valores de carga máxima suportada por cada corpo de prova, até ocorrer ruptura do mesmo, nos diferentes patamares de temperaturas analisado estão representadas na Figura 3. Os respectivos intervalos de confiança foram inseridos nas curvas.

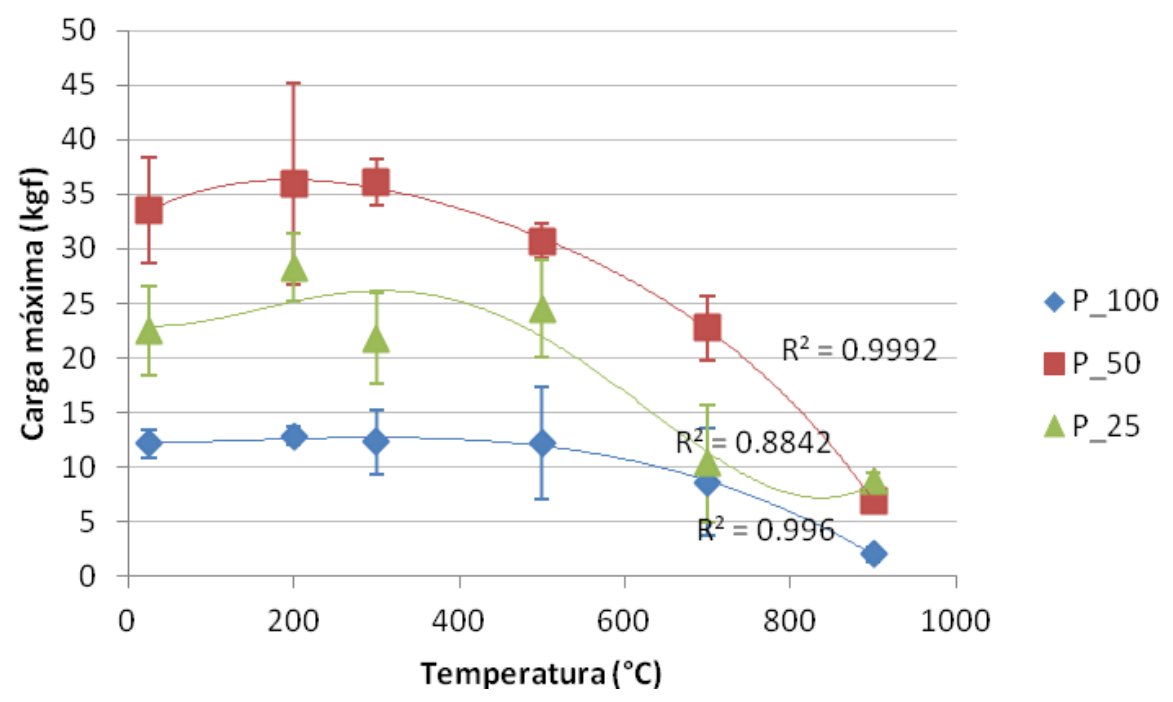

Figura 3. Carga máxima suportada por pelotas submetidas a diferentes temperaturas. Intervalo de confiança de $95 \%$.

Quando uma pelota autorredutora é aquecida até temperaturas de redução dos óxidos presentes, uma série de transformações ocorre em seu interior, sendo eliminados certos componentes na forma de produtos gasosos, assim como com a 
evolução da reação de redução de hematita para wustita, que passa de uma estrutura compacta $\left(\mathrm{Fe}_{2} \mathrm{O}_{3}\right)$ para a de cúbica de corpo centrado ("FeO"). Só esta variação estrutural provoca aumento de volume da ordem de $20 \%$. Isto provoca alterações físicas e físico-químicas na pelota, alterando-se as propriedades mecânicas e características microestruturais. O grau de intensidade dessas mudanças está relacionado com as condições de aquecimento, e depende diretamente da eliminação de umidade, eliminação de matéria volátil, eliminação de água de composição, formação de novas fases no sistema ligante [15] e inchamento estrutural.

A resistência à compressão das pelotas autoredutoras cai bruscamente quando são submetidas a altas temperaturas, principalmente após atingir $500^{\circ} \mathrm{C}$. Por volta dessa temperatura, começam a ocorrer reações de redução da hematita para wustita, aumento de porosidade pelo consumo de carbono contido e de decomposição dos hidratos dos aglomerantes, que conferem boa resistência a frio. Contudo, após certa temperatura, geralmente por volta de $1000^{\circ} \mathrm{C}$, a resistência das pelotas volta a subir, devido à ocorrência do processo de sinterização das partículas de ferro reduzido.

Takano e Mourão[2] encontraram valores entre $800-850^{\circ} \mathrm{C}$ para o começo da diminuição da resistência à compressão de pelotas autorredutoras, porém estavam baseados em resultados dentro de faixa de temperaturas acima de $800^{\circ} \mathrm{C}$. O presente trabalho corrobora outro trabalho posterior[17]. O comportamento crítico se deu entre $900-1000^{\circ} \mathrm{C}$. Singh e Björkman[18] encontraram resultados semelhantes para testes realizados em $950^{\circ} \mathrm{C}$.

A perda de massa, devido principalmente a eliminação de umidade, de água quimicamente ligada, e consumo de carbono está mostrada na Figura 4. Após $500^{\circ} \mathrm{C}$ essa perda é mais acentuada, como esperado, sendo coerente com a redução da resistência das pelotas submetidas a temperaturas maiores que esta.

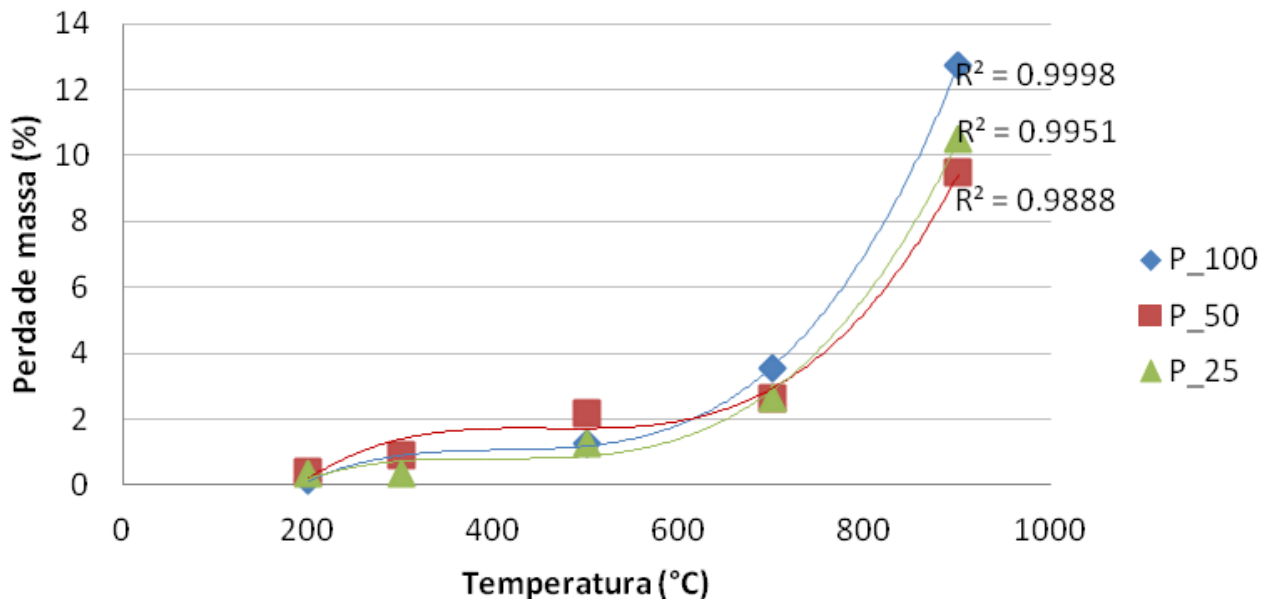

Figura 4. Perda de massa de cada lote em função das temperaturas submetidas.

Além disso, pelotas que possuíam maiores valores de resistência à compressão em temperatura ambiente também obtiveram maiores valores de resistência após a redução.

A Figura 5 mostra a resistência das amostras em função do tempo de permanência em cada patamar de temperatura. Com maiores tempos de permanência em determinada temperatura, há maior oportunidade para ocorrer as reações de redução e desidratação e, portanto, a carga máxima suportada pelas pelotas diminui gradativamente, porém não é tão intensa como a variação de temperatura. 


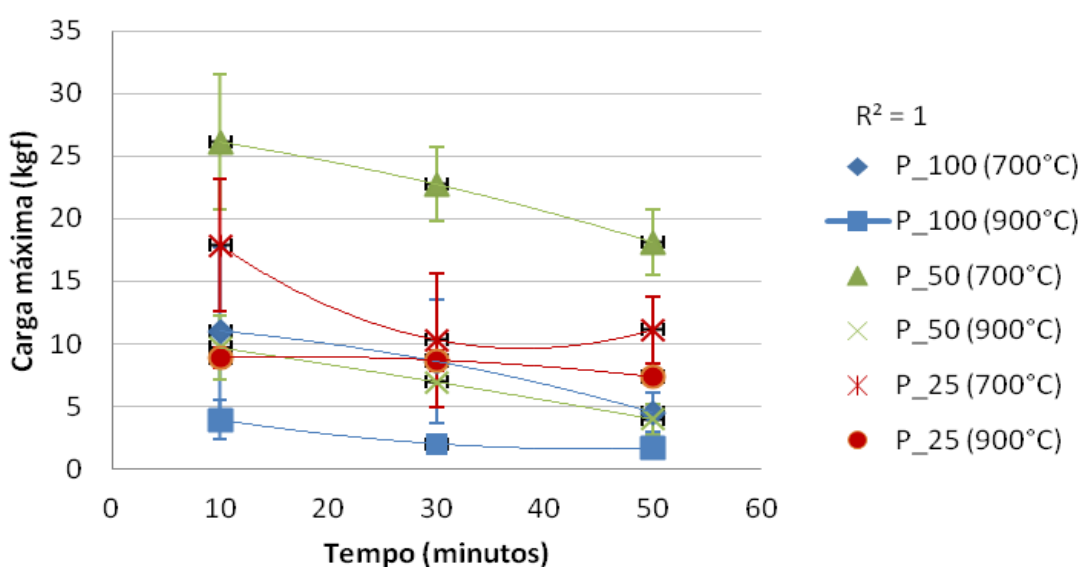

Figura 6. Carga máxima em diferentes tempos de permanência em cada patamar de temperatura. Intervalo de confiança de $95 \%$.

\section{CONCLUSÃO}

Pela análise dos resultados dos ensaios realizados, conclui-se que:

1. O comportamento mecânico de pelotas autorredutoras é melhorado com o aumento do tempo de cura, principalmente nos primeiros 3 dias, quando se utiliza cimento de alta resistência inicial (ARI) devido à fácil hidratação inicial dos componentes do cimento.

2. O valor da resistência compressão das pelotas autorredutoras, comparando-se as pelotas P-50 e P-100, está diretamente ligada à quantidade de coque presente nelas. Foi verificado um comportamento anômalo com as pelotas $P \_25$, que apresentou resistência à compressão menor que as pelotas $P \_50$, necessitando de maiores entendimentos.

3. A porosidade das pelotas varia de acordo com a quantidade de coque presente nelas. Os lotes com maiores teores de coque apresentaram maiores valores de porosidade, condizentes com os esperados.

4. A porosidade das pelotas aumentou significantemente nos primeiros dias de cura, em que ocorrem reações de hidratação e formação de gel coloidal de estrutura porosa.

5. A resistência à compressão das pelotas, assim como a perda de massa, cai bruscamente quando são submetidas a altas temperaturas, principalmente após atingir $500^{\circ} \mathrm{C}$, devido às reações de redução da hematita e de decomposição dos hidratos dos aglomerantes, corroborando com os trabalhos recentes da literatura.

6. A carga máxima suportada pelas pelotas diminui, porém com pouca intensidade, à medida que aumenta-se o tempo de permanência em determinada temperatura, pois há mais tempo para ocorrer as reações de redução e desidratação, diminuindo a resistência dos corpos de prova.

7. A resistência à compressão de pelotas semi-autoredutoras ( $P \_25$ e $\left.P \_50\right)$, à temperatura crítica de $900^{\circ} \mathrm{C}$, melhorou sensivelmente em relação às pelotas completamente auto-redutoras ( $\left.P_{-} 100\right)$, indicando boas perspectivas para suas utilizações práticas.

\section{Agradecimentos}

Os autores agradecem à Fundação do Instituto de Pesquisas Tecnológicas do Estado de São Paulo S/A, por financiar o projeto aqui apresentado por meio do edital 
no 08/2016 e ao Instituto de Pesquisas Tecnológicas do Estado de São Paulo S/A pelo uso da infraestrutura laboratorial para o desenvolvimento da pesquisa.

\section{REFERÊNCIAS}

[1] Midrex Technologies Inc. 2014 World Direct Reduction Statistics. Disponível em: http://www.midrex.com/assets/user/news/MidrexStatsbook201411.pdf

[2] TAKANO, C.; MOURÃO, M.B. Self-Reducing Pellets for Ironmaking: Mechanical Behavior. Mineral Processing and Extrative Metallurgy Review. Taylor and Francis. London, GB, 2003, v.24, no 3-4, pp. 233-252.

[3] MOURÃO, M.B.; TAKANO, C. Self-Reducing Pellets for Ironmaking: Reaction Rate and Processing. Mineral Processing and Extrative Metallurgy Review. Taylor and Francis. London,GB, 2003, v.24, no 3-4, pp.183-202.

[4] NASCIMENTO, R.C.; MOURÃO, M.B.; CAPOCCHI, J.D.T. Microstructures of selfreducing pellets bearing iron ore and carbon. ISIJ International. 1997, v. 37, no 11, pp 1050-1056.

[5] MERKLIN, K. E.; CHILDS, M. H.; Some factors influencing the physical qualities of iron ore pellets. AIME, 1961.

[6] CHU, M.-S.; YANG, X.-f.; SHEN, F.-m.; YAGI, J.-i.; NOGAMI, H. Numerical Simulation of Innovative Operation of Blast Furnace Based on Multi-Fluid Model. Journal of Iron and Steel Research International. 2006, v. 13, no 6, pp. 8-15.

[7] TSUGE, O, KIKUCHI, S., TOKUDA, K., Ito, S., KOBAYASHI, I., and Uragami, A., 2002, "Successful iron nuggets production at Itkm3 pilot plant", Ironmaking Conference Proceedings, ISS, 61, pp.511-519.

[8] MOURÃO, M; Análise do processo de redução de minério de ferro por carbono na forma de pelotas autorredutoras, tese de doutorado, USP, São Paulo, Brasil, 1988, 5-39.

[9] SRB, J; RUZICKOVÁ, Z. Pelletization of fines. 1. Ed. Praga, Elsevier, 1988.

[12] MANTOVANI, M. C. Comportamento a frio e a quente de pelotas autorredutoras de resíduo de aciaria elétrica. São Paulo, 1996. p. 25-30. Tese (Mestrado). Escola Politécnica, Universidade de São Paulo.

[10] DA SILVA, C. G. Comportamento a frio e a quente de pelotas autorredutoras a carvão vegetal. São Paulo, 1996. p. 4. Trabalho de Formatura. Escola Politécnica, Universidade de São Paulo.

[11] FERRAZ, H. M. Influência do aglomerante na cura de pelotas autorredutoras: aspectos microestruturais. São Paulo, 1999. Trabalho de Formatura. Escola Politécnica, Universidade de São Paulo.

[12] MANTOVANI, M. C. Comportamento a frio e a quente de pelotas autorredutoras de resíduo de aciaria elétrica. São Paulo, 1996. p. 25-30. Tese (Mestrado). Escola Politécnica, Universidade de São Paulo.

[13] GOKSEL, M.A., 1977, "Fundamentals of cold bond agglomeration process", Proceedings of the 2nd International Symposium on Agglomeration, Agglomeration 77, and Editor: K.V.S. Sastry, Berkley, 3, pp. 877-900

[14] GOKSEL, A., Coburn, J., and Kohut, J., 1991, "Recycling waste from iron-steel plants using PTC process, Ironmaking Conference Proceedings, ISS, pp. 97-112

[15] ATSUMI, E. Comportamento a quente de pelotas auto-redutoras de poeria de sinterização e de minério de ferro com variações do teor de aglomerantes. São Paulo, 1999. p. 12. Trabalho de Formatura. Escola Politécnica, Universidade de São Paulo.

[17] TAKANO, C.; NARITA, C.: MOURÃO, M. B. Alternatives binders for ore-carbon composite agglomerates: an analysis. Anais do $4^{\circ}$ Simpósio Brasileiro de Aglomeração de Minério de Ferro. ABM Week 2016.Riocentro RJ. ABM-SP

[18] SINGH, M., BJÖRKMAN, B. Swelling behaviour of cement-bonded briquettes-proposed model. ISIJ international, v. 44, n. 3, p. 482-491, 2004. 